\title{
Reflective Model of Teaching Indonesian for Foreign Speakers Integrated with Pragmatic Contexts
}

\author{
Yuliana Setyaningsih ${ }^{1}$, R. Kunjana Rahardi' ${ }^{2}$ Rishe Purnama Dewi ${ }^{3}$, Danang Sastria \\ Nugraha $^{4}$ \\ ${ }^{1,2}$ Master Program of Indonesian Language Education, Faculty of Teachers' Training and \\ Education, Sanata Dharma University, Yogyakarta, Indonesia \\ ${ }^{3,4}$ Undergraduate Program of Indonesian Language and Literature Education, Faculty of \\ Teachers' Training and Education, Sanata Dharma University, Yogyakarta, Indonesia
}

1yulia@usd.ac.id,yuliapbsi@gmail.com

\begin{abstract}
Enthusiasm to integrate pragmatic contexts in BIPA learning is increasing. It is understandable because communicative competence in BIPA learning cannot be limited to understanding the Indonesian grammatical rules, memorizing the list of vocabulary, and learning the pronunciation of the words. However, how to integrate pragmatic contexts in the learning materials is not a simple matter. This research aims to describe the reflective learning model used in BIPA learning which integrates pragmatic contexts. The approach used in this research is qualitative. The research data are the needs analysis of the reflective learning model and its rationale. The research data sources are gathered from many references and opinions of experts of high authority in BIPA learning. The researchers' pedagogic intuition also greatly contributes to the data for analysis. The collected data are classified and typified. Data analysis is carried out when the data have been classified and typified properly. The analysis method used in this research is the content analysis method. The research results describe the needs analysis to develop a reflective learning model and its rationale in the BIPA learning materials integrating pragmatic contexts. This research has a practical benefit to provide an alternative model of BIPA learning. Theoretically, this research contributes greatly to the development of linguistics, particularly in regards to BIPA learning.
\end{abstract}

Keywords: Reflective Learning Model, Pragmatic Contexts, Foreign Speakers, Teaching Model

\section{PENDAHULUAN}

Berkomunikasi pada hakikatnya tidak terlepas dari konteks pragmatik. Pembelajaran bahasa Indonesia bagi penutur asing (BIPA) yang melepaskan konteks pragmatik membuat komunikasi tidak terbangun utuh [1]. Membangun komunikasi yang utuh tidak cukup dengan memahami kaidah-kaidah kebahasaan, menguasai kosa kata, dan mampu melafalkan kata-kata dengan benar, melainkan juga menangkap makna sesuai dengan konteksnya. Mengingat peran 
konteks begitu penting dalam menentukan maksud berkomunikasi, pembelajaran BIPA perlu mengintegrasikan konteks [2].

Dari pencermatan tim peneliti terhadap sejumlah referensi, ditemukan bahwa pembelajaran BIPA yang selama ini berjalan belum sepenuhnya menekankan pada pendekatan komunikatif. Pembelajaran BIPA masih cenderung menekankan aspek kebahasaan yang cenderung diskret. Maksudnya adalah bahwa dominasi elemen-elemen kebahasaan lebih menonjol daripada keterampilan berkomunikasi dengan bahasa sesuai dengan konteksnya [3]. Pembelajaran bahasa untuk berkomunikasi yang demikian ini tentu tidak akan dapat membangun kompetensi komunikatif yang memadai pada para pembelajar BIPA.

Berangkat dari kenyataan itulah, tim peneliti mengangkat pendekatan reflektif dalam pembelajaran BIPA. Pendekatan refektif dalam pembelajaran BIPA terdiri atas komponen (1) konteks pembelajaran, (2) pengalaman belajar, (3) refleksi pembelajaran, (4) evaluasi pembelajaran, dan (5) aksi hasil refleksi dan evaluasi pembelajaran [4].

Konteks merupakan salah satu komponen penting yang perlu dibangun agar tercipta suasana pembelajaran yang dapat mendukung pencapaian kompetensi berbahasa [3]. Konteks yang dibangun secara baik ketika mengawali proses pembelajaran diyakini akan mempermudah tahapan-tahapan pembelajaran selanjutnya.

Komponen berikutnya adalah pengalaman pembelajaran. Komponen pengalaman pembelajaran ini merupakan kegiatan inti yang berisi kegiatan pembelajaran yang sesuai model dan metode yang ditentukan. Pemilihan model dan metode pembelajaran yang tepat sangat penting karena akan sangat menentukan kualitas pembelajaran dan menjamin pencapaian kompetensi yang telah ditetapkan [5]. Komponen ketiga dari siklus pembelajaran reflektif adalah refleksi pembelajaran. Refleksi pembelajaran menjadi bagian yang sangat penting dalam siklus karena dengan refleksi itu para pembelajar BIPA memaknai pengalaman belajar, melakukan konsientiasi terhadap pengalaman belajar tersebut dan mengonstruksinya dalam diri pembelajar BIPA itu. Dengan demikian, dapat ditegaskan bahwa refleksi pembelajaran sangat esensial untuk dilaksanakan. Pembelajaran BIPA yang tidak mengabaikan refleksi diyakini dapat membawa para pembelajar BIPA pada penguasaan kompetensi yang optimal. Pembelajaran BIPA tanpa refleksi tentu juga tidak memberikan manfaat yang maksimal kepada para pembelajar BIPA.

Selanjutnya langkah keempat dalam siklus pembelajaran reflektif adalah evaluasi. Evaluasi dimaksudkan untuk mendapatkan feedback yang bermanfaat bagi pengembangan pembelajaran. Masukan-masukan dalam feedback itu harus dapat digunakan untuk membuat adjustment atau penyesuaian-penyesuaian dalam pembelajaran. Oleh karena itu, evaluasi pembelajaran harus mencakup aspek kognisi, aspek psikomotoris, dan aspek sikap. Selain itu, evaluasi pembelajaran juga harus bersifat autentik. Artinya, evaluasi pembelajaran tersebut harus menekankan pada proses bukan semata-mata pada hasil sehingga hasilnya bersifat nyata atau autentik.Langkah terakhir dalam siklus pembelajaran reflektif adalah aksi. Aksi merupakan tindak lanjut dari kegiatan refleksi dan evaluasi. Para pembelajar BIPA dapat menuangkan berbagai gagasan, perasaaan, keinginan dalam bentuk tindakan nyata. Aksi tersebut dapat dituangkan dalam bentuk poster, memo, slogan, motto, yang terkait dengan materi pembelajaran.

Selanjutnya teori yang melandasi penelitian ini adalah teori pragmatik [6], teori konteks, dan teori tentang pembelajaran komunikatif BIPA. Pragmatik sebagai perspektif dapat dipahami sebagai cara memandang bahasa untuk memahami maksud penutur dalam kaitan dengan unsur-unsur eksternal bahasa itu [7]. Dengan perspektif itu, maksud penutur dalam berbahasa tidak dapat dimaknai hanya dengan memahami aspek-aspek internal bahasa, tetapi juga aspek-aspek eksternal bahasa itu. Selanjutnya perlu juga disampaikan bahwa 
pragmatik sebagai cabang ilmu merupakan cabang terbaru dari ilmu linguistik yang mempelajari maksud penutur [8].

Dengan demikian kajian-kajian yang selayaknya dilakukan dalam pragmatik adalah kajian-kajian tentang maksud penutur itu dalam berkomunikasi. Kajian maksud sangat bertalitemali dengan konteks, karena tanpa konteks maksud penutur itu tidak akan dapat diidentifikasi secara benar. Konteks dalam studi pragmatik dibedakan menjadi empat, yakni sosial, sosietal, situasional, dan kultural [9]. Keempat jenis konteks dalam studi pragmatik itu masing-masing memiliki fokus, tetapi keempat-empatnya saling bertautan dan tidak dapat dipisahkan satu dengan yang lainnya. Demikian pula, sebuah pertuturan sangat dimungkinkan mengandung beberapa jenis konteks yang disebutkan di atas itu. Selanjutnya, perlu disampaikan bahwa di dalam setiap jenis konteks itu terdapat sejumlah elemen pembangun konteks. Demikian pula, di dalam setiap jenis konteks tersebut terdapat sejumlah fungsi konteks. Elemen-elemen dan fungsi-fungsi kopnteks itulah yang sangat penting dipahami oleh para pembelajar BIPA.

Belajar berkomunikasi dalam bahasa Indonesia yang mengabaikan keempat jenis konteks dalam pragmatik di atas, tidak akan membuahkan hasil yang optimal. Para pembelajar BIPA tidak akan memiliki kompetensi komunikatif yang memadai, dan yang dimiliki cenderung hanya akan berupa rangkaian kaidah-kaidah kebahasaan yang tentu saja tidak akan secara fungsional membangun kemampuan berkomunikasi. Perspektif itulah yang menuntun tim peneliti untuk mengembangkan materi pembelajaran BIPA terintegrasi dengan konteks pragmatik ini [10]. Pengembangan materi pembelajaran BIPA ini juga tidak lepas dari ketentuan dari CEFR (Common European Framework of Reference for Language) [11]. Selanjutnya, hasil pengembangan materi di atas diterapkan dalam pembelajaran BIPA dengan pendekatan komunikatif menerapkan model kooperatif dalam paradigma pedagogi reflektif Ignasian.

\section{METODE}

Pendekatan yang digunakan dalam penelitian ini adalah pendekatan kualitatif. Data penelitian ini berupa kebutuhan pengembangan model pembelajaran reflektif dan rasionalisasinya yang diperoleh melalui observasi dokumen yang berupa buku teks pembelajaran BIPA. Sumber data penelitian ini adalah berbagai sumber referensi yang berupa buku teks bahasa Indonesia untuk penutur asing (BIPA) yang diterbitkan oleh Badan Bahasa Republik Indonesia. Keterangan pakar sebagai otoritas terkait pembelajaran BIPA. Berbagai informasi dari beberapa pengelola BIPA menjadi sumber data dalam penelitian ini. Intuisi pedagogis tim peneliti juga berkontribusi besar dalam menciptakan data untuk dianalisis [12]. Setelah data terkumpul, langkah selanjutnya adalah klasifikasi dan tipifikasi data. Analisis data dilakukan setelah data benar-benar tersaji secara baik ditandai dengan klasifikasi dan tipifikasi yang teliti dan rapi. Metode analisis yang digunakan dalam penelitian ini adalah metode analisis isi [13].

\section{HASIL DAN PEMBAHASAN}

Hasil pengembangan materi pembelajaran BIPA yang dilakukan oleh tim peneliti selanjutnya diterapkan dalam pembelajaran BIPA dengan pendekatan pembelajaran komunikatif dalam paradigma pedagogi refektif Ignasian yang terdiri atas komponen-komponen berikut: (1) konteks pembelajaran, (2) pengalaman belajar, (3) refleksi pembelajaran, (4) evaluasi pembelajaran, dan (5) aksi pembelajaran. Pembelajaran BIPA yang dilakukan dengan 
menerapkan pendekatan komunikatif dalam paradigma pedagogi reflektif Ignasian seperti disampaikan di atas akan sangat memungkinkan para pembelajar menguasai aspak-aspek keterampilan yang tentu saja sangat gayut dengan tujuan mereka belajar berbahasa Indonesia. Aspek-aspek kognisi sama sekali tidak diabaikan dalam pembelajaran di atas, tetapi fokus kegiatan adalah pada kegiatan latihan berbahasa dalam konteks sosial yang sesungguhnya.

Kegiatan membangun konteks pembelajaran pada bagian pertama siklus, para pembelajar BIPA melakukan empat kegiatan sebagai berikut: (a) Mahasiswa berproses dalam kegiatan curah gagasan (brainstorming) terkait permasalahan aktual tentang lingkungan hidup; (b) Mahasiswa dimotivasi untuk belajar dengan menonton cuplikan video 'permasalahan lingkungan hidup' yang mengandung pertuturan terkait konteks situasional; (c) Mahasiswa merespons lontaran pertanyaan dosen terkait video yang telah ditayangkan; (d) Mahasiswa mengidentikasi tujuan dan manfaat pembelajaran pragmatik tentang konteks situasional. Dengan kegiatan-kegiatan dalam membangun pengalaman itu, dipastikan bahwa baik pembelajar maupun instruktur BIPA memahami secara pasti, apa yang hendak dipelajari pada langkah pembelajaran selanjutnya. Kegiatan ini penting karena mahasiswa akan terbangun motivasi belajarnya ketika tujuan dan manfaat pembelajaran dipahami secara rinci. Demikian pula, pembelajaran yang akan dilaksanakan akan menjadi sangat bermakna karena kaitan dengan materi sebelumnya telah dibangun dalam kegiatan membangun konteks pembelajaran tersebut.

Pengalaman belajar yang didapat para pembelajar BIPA, mereka dapat melaksanakan kegiatan pembelajaran yang berfokus pada siswa (student-oriented). Instruktur harus memastikan dirinya memiliki peran sebagai pemotivator dan sebagai fasilitator. Selain harus meyakinkan dirinya dengan dua peran pokok dalam mengajar tersebut, instruktur juga harus mampu menjadi inovator [14]. Dengan peran instruktur yang demikian itu, dipastikan para pembelajara BIPA akan dapat belajar berbahasa Indonesia dengan baik. Mereka tidak akan bosan dengan kegiatan pembelajaran dan materi pembelajaran yang disiapkan oleh instruktur. Dengan langkah pembelajaran yang demikian itu, pembelajaran BIPA tidak akan lagi terjadi secara diskret, berfokus pada kaidah-kaidah bahasa, melainkan akan berjalan secara komunikatif. Praktik belajar berbahasa atau berkomunikasi dengan bahasa yang mengintegrasikan konteks pragmatik akan terjadi dengan sebaik-baiknya.

Langkah-langkah konkret dalam kegiatan memberikan pengalaman belajar itu dapat dilihat selengkapnya sebagai berikut: (a) Mahasiswa dihadapkan pada situasi tuturan yang mengandung problema terkait konteks situasional "permalasahan lingkungan hidup"; (b) Mahasiswa mengurai tuturan yang mengandung problema terkait konteks situasional tersebut; (c) Mahasiswa membagi tugas berdasarkan hasil penguraian problema terkait konsteks situasional; (d) Mahasiswa mengeksplorasi jawaban sesuai dengan tugas belajar yang dibagikan tentang problema terkait konteks situasional; (e) Mahasiswa secara individual menata hasil eksplorasi yang telah dilakukan tentang problema terkait konteks situasional; (f) Mahasiswa secara berkelompok mendiskusikan hasil eksplorasi dari setiap individu tentang problema terkait konteks situasional; (g) Mahasiswa mempresentasikan hasil diskusi kelompok tentang problema terkait konteks situasional; dan (h) Mahasiswa merumuskan simpulan jawaban tentang problema terkait konteks situasional dengan pendampingan dosen.

Kegiatan refleksi sangat penting dilakukan dalam pembelajaran BIPA. Kegiatan refleksi dalam pempelajaran ini disampaikan dengan langkah-langkah berikut: (a) Mahasiswa berefleksi pribadi menuliskan catatan reflektif pada form isian yang disediakan dosen tentang pembelajaran pragmatik terintegrasi dengan konteks situasional; (b) Mahasiswa membagikan hasil refleksinya dengan teman sejawat di dalam kelas tentang pembelajaran pragmatik terintegrasi dengan konteks situasional; (c) Mahasiswa merumuskan sesuatu yang menyentuh 
dirinya terkait dengan refleksi pembelajaran pragmatik situasional. Dengan kegiatan reflektif seperti yang disampaikan di depan, para pembelajar BIPA akan dapat melakukan konsientiasi atau pengendapat atas apa saja yang baru saja dipelajari dalam kegiatan pengalaman belajar [15]. Setelah konsientiasi dilakukan, para pembelajar BIPA akan melakukan proses konstruksi di dalam diri masing-masing. Dalam pandangan konstruktivistik, kegiatan konsientiasi dan kegiatan mengonstruksi demikian inilah yang akan banyak bermanfaat bagi perkembangan kemampuan berbahasa para pembelajar BIPA.

Langkah keempat dalam siklus pedagogi reflektif adalah langkah aksi dalam pembelajaran. Hasil dari sebuah refleksi tidak boleh berhenti sebagai sesuatu yang tidak dilaksanakan langsung dalam kegiatan nyata. Aksi berbelarasa sebagai kelanjutan dari kegiatan refleksi atas sebuah peristiwa, misalnya saja, merupakan salah satu tindakan konkret yang harus dilakukan dalam proses pembelajaran [16]. Kepedulian sosial dari para pembelajar BIPA sangat pentimng untuk ditumbuhkan agar mahasiswa benar-benar memaknai bahasa sebagai sebuah peristiwa sosial yang nyata. Dari pengamatan tim peneliti, kegiatan berbela rasa demikian ini sangat jarang dilakukan dalam pembelajaran BIPA. Akibatnya, para pembelajar BIPA tidak benar-benar mampu berbahasa dan berkomunikasi sesuai dengan konteks sosialnya. Langkah aksi selengkapnya disampaikan sebagai berikut: (a) Mahasiswa merancang rencana aksi sebagai kelanjutan dari hasil refleksi tentang pembelajaran pragmatik terintegrasi dengan konteks situasional; (b) Mahasiswa merealisasi rancangan aksinya dalam bentuk media-media yang relevan untuk diterapkan dalam tindakan nyata terkait pembelajaran pragmatik terintegrasi dengan konteks situasional; (c) Mahasiswa melaksanakan aksi sesuai dengan rencana dan media relevan yang telah disiapkan sebelumnya terkait pembelajaran pragmatik terintegrasi dengan konteks situasional.

Langkah terakhir dalam siklus pedagogi reflektif Ignasian adalah langkah evaluasi. Kegiatan evaluasi sangat penting dilakukan untuk mengetahui sejauh manakah kompetensi yang hendak dicapai dalam kegiatan pembelajaran itu benar-benar telah tercapai. Pembelajaran BIPA yang benar-benar menjamin pencapaian kompetensi peserta didik, diyakini pembelajaran itu akan menjadikan mereka mampu berkomunikasi dengan bahasa Indonesia sesuai dengan konteks sosialnya. Pembelajaran BIPA yang kurang bisa melahirkan para pembelajar yang mampu berkomunikasi dengan bahasa Indonesia secara efektif, harus disempurnakan kembali agar menjadi lebih baik. Penyempurnaan dilakukan hanya setelah evaluasi dilaksanakan secara benar [17]. Dengan demikian semakin kelihatan betapa pentingnya kegiatan evaluasi dalam proses pembelajaran bahasa.

Langkah-langkah evaluasi disampaikan sebagai berikut: (a) Mahasiswa melaksanakan evaluasi tentang pembelajaran pragmatik terintegrasi dengan konteks situasional yang disiapkan dosen sesuai dengan indikator pencapaian kompetensi; (b) Mahasiswa mendapatkan hasil evaluasi dan balikan-balikan hasil evaluasi dari dosen tentang pembelajaran pragmatik terintegrasi dengan konteks situasional; (c) Mahasiswa melaksanakan pekerjaan remidi bagian-bagian tertentu dalam pembelajaran pragmatik terintegrasi dengan konteks situasional yang belum sepenuhnya dikuasi dengan baik.

\section{SIMPULAN}

Sebagai simpulan perlu disampaikan bahwa pembelajaran BIPA untuk melatih para peserta berkomunikasi dengan bahasa Indonesia tidak dapat dilakukan dengan terlalu diskret. Dikatakan demikian karena pembelajaran BIPA yang demikian itu cenderung akan menuntun para pembelajaran ke dalam pemahaman aspek-aspek kognitif atau aspek-aspek pengetahuan 
bahasa Indonesia. Pembelajar BIPA harus dilatih untuk berkomunikasi dengan bahasa agar mereka dapat berinteraksi secara sosial dengan bahasa. Berkaitan dengan tujuan itu, pembelajar BIPA harus memahami konteks pragmatik yang mencakup konteks sosial, konteks sosietal, konteks situasional, dan konteks kultural. Pemahaman konteks pragmatik itu dilakukan dengan menerapkan pendekatan pembelajaran komunikatif dengan model reflektif berparadigma pedagodi Ignasian. Dengan pembelajaran yang demikian itu, bukan saja aspekaspek kognisi yang dikuasi oleh para pembelajar BIPA, tetapi juga aspek-aspek keterampikan, khususnya keterampilan berbahasa untuk berkomunikasi sesuai dengan konteks pragmatiknya.

\section{REFERENCES}

[1] K. Saddhono, "Cultural and social change of foreign students in Indonesia: The influence of Javanese Culture in Teaching Indonesian to Speakers of Other Languages (TISOL)," in IOP Conference Series: Earth and Environmental Science, 2018.

[2] N. Taguchi, “'Contextually' speaking: A survey of pragmatic learning abroad, in class, and online," System, 2015.

[3] K. Saddhono, "Integrating culture in Indonesian language learning for foreign speakers at Indonesian universities," J. Lang. Lit., 2015.

[4] K. L. Guthrie and H. McCracken, "Reflective pedagogy: Making meaning in experiential based online courses," Journal of Educators Online. 2010.

[5] I. Suyitno, G. Susanto, M. Kamal, and A. Fawzi, "Teaching Materials and Techniques Needed by Foreign Students in Learning Bahasa Indonesia," ISLLAC J. Intensive Stud. Lang. Lit. Art, Cult., 2017.

[6] Y. Setyaningsih and R. K. Rahardi, "Quality Of Arguments Used In The First-Round Presidential Debate: Critical Pragmatics And Stephen Toulmin's Perspective," Int. J. Eng. Adv. Technol., vol. 8, no. 5C, pp. 716-725, 2019.

[7] R. K. Rahardi, "Pragmatic Perspective on Phatic Functions and Language Dignity," Int. J. Eng. Adv. Technol., vol. 8, no. 5C, May 2019, pp. 261-268, 2019.

[8] R. K. Rahardi, "Pragmatic Phenomena Constellation in Specific Culture Dimension Language Study," Int. J. Humanit. Stud., 2017.

[9] J. Mey, Concise encyclopedia of pragmatics. 1998.

[10] R. K. Rahardi, "Elemen dan Fungsi Konteks Sosial, Sosietal, dan Situasional dalam Menentukan Makna Pragmatik Kefatisan Berbahasa," in Prosiding Seminar Tahunan Linguistik Universitas Pendidikan Indonesia (SETALI 2018), 2018, pp. 654-658.

[11] R. K. Ningrum, H. J. Waluyo, and R. Winarni, "BIPA (Bahasa Indonesia Penutur Asing) Sebagai Upaya Internasionalisasi Universitas di Indonesia," Procedings Educ. Lang. Int. Conf., 2017.

[12] M. Mahsun, "Metode Penelitian Bahasa," Jakarta PT Raja Grafindo Persada, 2005.

[13] S. Arumdyahsari, W. Hs, and G. Susanto, "Pengembangan Bahan Ajar Bahasa Indonesia Bagi Penutur Asing (BIPA) Tingkat Madya,” J. Pendidik. Teor. Penelitian, dan Pengemb., 2016.

[14] R. Ramliyana, "Membangkitkan Motivasi Belajar Bahasa Indonesia bagi Penutur Asing (BIPA) Melalui Media Komik," Dialekt. J. Bahasa, Sastra, dan Pendidik. Bhs. dan Sastra Indones., 2016.

[15] J. C. Richards, "Towards reflective teaching," English Teach. J., 1995.

[16] I. \& A. S. Desi, Rahayu \& Solihin, "Peningkatan Keterampilan Sosial Anak Usia Dini Melalui Permainan Tradisional,” Antol. UPI, 2016. 
[17] E. P. Saputro and S. Arikunto, "Keefektifan manajemen program pembelajaran BIPA (Bahasa Indonesia bagi Penutur Asing) di Kota Yogyakarta," J. Akuntabilitas Manaj. Pendidik., 2018. 